\title{
Complementary Methods for Evaluation of Yttria Stabilized Zirconia Coatings used as Thermal Barrier Coating
}

\author{
Adriana Savin $1,{ }^{*}$ - Mihail Liviu Craus 1,2 - Vitaly Turchenko ${ }^{2}$ - Frantisek Novy ${ }^{3}-$ \\ Aura C. Mocanu ${ }^{4}$ - Marian Soare ${ }^{4}$ - Janez Grum ${ }^{5}$ - Oleksandr Sergiyovich Doroshkevich²,6 \\ ${ }^{1}$ National Institute for R\&D for Technical Physics, NDT Department, Romania \\ 2Joint Institute for Nuclear Research, Frank Laboratory for Neutron Physics, Russia \\ 3 University of Žilina, Faculty of Mechanical Engineering, Slovak Republic \\ 4SC Nuclear NDT Research and Services SRL, Romania \\ 5 University of Ljubljana, Faculty of Mechanical Engineering, Slovenia \\ ${ }^{6}$ Donetsk Institute for Physics and Engineering, O. O. Galkin NAS of Ukraine, Ukraine
}

The paper proposes the use of a nondestructive electromagnetic (NDE) method for evaluation of zirconia coating on AISI 316L, based an electromagnetic (EM) sensor with metamaterial lens. Metamaterials (MM), namely conical Swiss roll (CSR), operated in radiofrequency range can serve as EM flux concentrators. EM lens composing the sensors are designed on the basis of Fourier optic principles and allows the enhancement of the spatial resolution of method in order to evaluate quality of surface /adhesion coating-support. Complementary methods such as scanning electron microscopy (SEM), $X$ ray diffraction (XRD) and neutron diffraction (ND) are employed for the studies of the samples taken into consideration.

Keywords: $\mathrm{ZrO}_{2}$-based ceramics, yttria, scanning electron microscopy, neutron diffraction, $\mathrm{X}$-ray diffraction, electromagnetic test

\author{
Highlights \\ - $\quad$ Yttria stabilized zirconia (YSZ) layers are deposited on stainless steels in order to be used as thermal barrier coatings. \\ - $\quad$ SEM, XRD and ND are used to characterize the deposited films as well as the support. \\ - A new sensor with metamaterial able to obtain information about films quality is used to evaluate the quality of surface/ \\ adhesion coating support. \\ - $\quad$ The presence of agglomeration of oxides and nonadherence regions were emphasized.
}

\section{INTRODUCTION}

Thermal-barrier coatings (TBCs) is used for improving efficiency and power of metallic parts employed in high temperature environment as gasturbine engines usually used in transportation, energy, and defense sectors [1]. TBC is ceramic coating deposited on metallic surfaces, containing or not thermally grown oxide (TGO). The substrate-ceramic interface is the weakest part of TBC and can exhibit fractures under the action of thermal shock. Previous papers have been focused on behavior analysis of TGO as intermediary layer and later, on the improving of the surface of the top layer submitted to loadings during functioning. The optimization of the substrate surface topography is preferably based on a more complete characterization in order to achieve a reasonable balance between the level of induced delamination stresses, mechanical bonding as well as a minimization of the defect size.

For characterization and monitoring of TBC failure, detection of their delamination, nondestructive electromagnetic (NDE) methods are used; most of these are based on optical principles including mid- infrared reflectance [2], luminescence spectroscopy [3] and elastic optical scattering [4]. These methods allowed detection of TBC delamination and pre-spall condition, but there are no longer investigated. Due of remarkable structural properties of zirconia $\left(\mathrm{ZrO}_{2}\right)$ based ceramics, in current technological applications (dental material, solid-oxide fuel-cell design for oxygen detection, nuclear waste confinement, medical prosthesis, etc.) $\mathrm{ZrO}_{2}$ are preferred due to their advanced mechanical properties such as high-fracture toughness and bulk modulus, corrosion resistance, chemical inertness, low chemical conductivity and biocompatibility [5] and [6]. Laminar structures of yttria stabilized zirconia - thermal-barrier coatings (YSZ-TBC) layers deposited on stainless steels are typically porous and the pore size and character depends on the process parameters. A decreasing of global coating porosities is preferred; especially those opened at the surface, in order to reduce to minimum the permeability of coating to oxidation. $\mathrm{ZrO}_{2}$ doped with rare earths oxides is considered a good TBC material [7] due of its low thermal conductivity $(\sim 2.0$ $\mathrm{m}^{-1} \mathrm{~K}^{-1}$ at $1100{ }^{\circ} \mathrm{C}$ ), refractory, chemical inertness, and compatible thermal expansion coefficient [6] 
and [8] with metallic support. Zirconia stabilized in tetragonal phase, namely tetragonal zirconia polycrystal (TZP) have $\mathrm{CeO}_{2}$ and $\mathrm{Y}_{2} \mathrm{O}_{3}$ [9] and [10] as stabilizers. The dimensions of crystallites are in the range of hundreds of nanometers, conferring a high resistance to breaking, so that YSZ shows high resistance to thermal shocks and fatigue up to $1150{ }^{\circ} \mathrm{C}$ temperature [11]. It is known that three low-pressure polymorphic forms of zirconia [6] and [12] can be found: monoclinic state (stable for temperatures below $1170{ }^{\circ} \mathrm{C}$ ), $P 2_{1} / c$; tetragonal phase, $P 4_{2} / n m c$ (stable for temperature between $1170{ }^{\circ} \mathrm{C}$ and $2370^{\circ} \mathrm{C}$ ) and the cubic, $F m-3 m$ phase (for temperature above $2370^{\circ} \mathrm{C}$ ) [13]. Despite the success of zirconia in many new applications, it has become apparent that certain zirconia compositions can also have one weakness - their tendency to low temperature degradation in the presence of moisture. Under external stress, as grinding or impact, transition from the tetragonal $(\mathrm{t})$ to monoclinic $(\mathrm{m})$ phase can appear at normal temperatures, being followed by an increase of volume of $3 \%$ to $12 \%$, causing compressive stress of YSZ coating [14] and [15].

New nanocomposites, in which nanometer sized second phase particles are dispersed within a ceramic matrix and/or at grain boundaries, have shown significant improvements in strength and creep resistance, even at high temperatures, and assure an exciting future in different technological fields. This paper proposes to present an electromagnetic (EM) method for evaluation of $\mathrm{ZrO}_{2}$ coating (to differentiate the areas with good/inferior coating quality) on stainless steels using an EM sensor with metamaterial (MM) lens. The novelty consists in the type of deposition of zirconia layers, without intermediate TGO substrate, the thin thickness of the deposition and the way of nondestructive testing. Alternative methods of characterization are involved as scanning electron microscopy (SEM), X-ray diffraction and metallography [16].

\section{THEORETICAL PRINCIPLES OF ELECTROMAGNETIC SENSORS WITH MM LENS}

\subsection{Electromagnetic Sensor}

The EM NDE is a well-known method for the quality evaluation of conductive pieces and structures with the aim of discontinuities detection cracks, inclusions, voids, etc. It is based on the induction of eddy current in the object to be evaluated, of which circulation is modified when there are regions with electrical conductivity and/or magnetic permeability different from that of the medium.

The metamaterials, electromagnetic structures with distinguished properties have started to be studied especially in the last few years (tuned mass absorbers or use for structural health monitoring (SHM). MMs [17] can provide an engineered response to EM radiation that is not available from the class of naturally occurring materials. The size of the structure is typically smaller than the free space wavelength of incoming EM waves. Nowadays, multitudes of MM structural elements type are known, conferring special EM properties. Depending on the frequency of the incident EM field, the type and geometrical shape MM may have a high relative magnetic permeability either positive or negative [18] and [19] and allow the EM waves amplification [20]. These properties strongly depend on the geometry of metamaterials more than on its composition [20] and [21].

Due to their wide application in perfect lens [19], MM must be characterized as an effective homogeneous slab with $\varepsilon_{\text {eff }}$ and $\mu_{\text {eff, }}$, that can be calculated from the scattering parameters ( $S$-parameters) data. The matrices containing the $S$-parameters express the changes of EM energy propagating through a multiport transmission line if EM wave meets the impedance differing from the line's characteristic impedance. For two-port line, $S$-parameter express the response to reflected $\left(S_{11}\right.$, $\left.S_{22}\right)$ and transmitted $\left(S_{12}, S_{21}\right)$ EM signal at each port, [22]. S parameters have been measured using Agilent type 4395A coupled with Agilent $S$ - parameter test kit $87511 \mathrm{~A}$. Assuming the continuous material is characterized by $n$ refractive index and $Z$ impedance relatively simple analytic expression can be found relating $n$ and $Z$ of a slab to the $S$ parameters [23]:

$$
\begin{gathered}
n=\frac{1}{k d} \cos ^{-1}\left[\frac{1}{2 S_{21}}\left(1-S_{11}^{2}+S_{21}^{2}\right)\right], \\
Z=\sqrt{\frac{\left(1+S_{11}\right)^{2}-S_{21}^{2}}{\left(1-S_{11}\right)^{2}-S_{21}^{2}}}
\end{gathered}
$$

where $d$ represents the dimension of unit cell of MM.

In the case of conical Swiss roll CSR, dimension of $d$ is $20 \mathrm{~mm}$ (as the diameter of the large basis of the CSR) and $k$ represents the wavenumber of the incident electromagnetic wave in free space, $n$ and $Z$ are related to dielectric permittivity and magnetic permeability by the relations [23] and [24]:

$$
\varepsilon=\frac{n}{Z}
$$




$$
\mu=n Z,
$$

where $n$ and $Z$ have complex values.

The EM sensor is an absolute send-receiver type [18] and [22], and has the principle scheme given in Fig. 1a and its construction in Fig. 1b. EM sensors with MM lens is made using CSR [22]. The operation frequencies depends both by the constitutive parameters of MM lens as well as by the polarization of the incident EM field (transversal electric $\mathrm{TE}_{\mathrm{z}}$ or transversal magnetic $\mathrm{TM}_{\mathrm{z}}$ ), in this case $\mathrm{TMz}$ polarized at normal incidence. The emission part of the sensor is made from a single turn rectangular coil with $20 \mathrm{~mm}$ $\times 60 \mathrm{~mm}$ dimensions, placed at $25 \mathrm{~mm}$ distance from the lens. The reception coil sensors has one turn with 1 $\mathrm{mm}$ average diameter placed in the focal image point, converting the localized energy into an electromotive force (EMF). a)

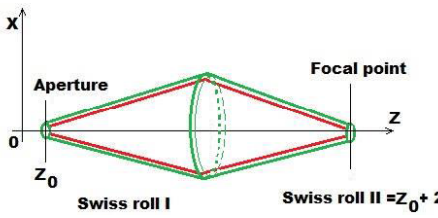

Fig. 1. Sensor with MM lens: a) principle scheme; b) physical realization

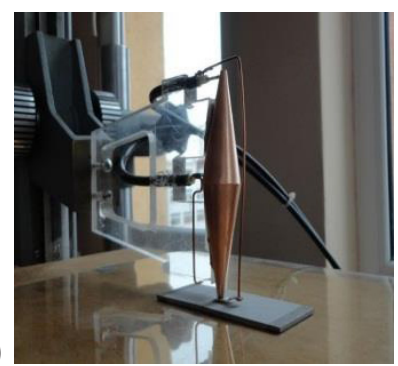

Using Fourier optic basics principles, the field in focal plane of the lens made by two CSR is:

$H\left(x, y, z_{0}+2 l\right)=$

$\frac{H_{0}}{\pi^{2}} e^{j\left(\frac{k_{b}+k_{a}}{2} x+\frac{k_{b}+k_{a}}{2} y\right)} \frac{\sin \left(\frac{k_{b}-k_{a}}{2} x\right)}{x} \frac{\sin \left(\frac{k_{b}-k_{a}}{2} y\right)}{y}$,

when $z_{0}<<\lambda$ ( $\lambda$ is the wave length of the incident field), $H_{0}$ being the amplitude of incident magnetic field.

In order to enhance spatial resolution, to ensure paraxial incident beam, in front of the sensor is placed a conductive screen having a circular aperture made from perfect electric conductive (PEC) material with very small diameter. The diameter of focal spot of MM lens is [25]:

$$
D=\frac{4 \pi}{\left(k_{b}-k_{a}\right)},
$$

and it is equal with CSR small basis diameter i.e. $3.2 \mathrm{~mm}$, with $k_{a}, k_{b}$ defined in [22]. When the lens is displaced along the scanning axis $x$, Fig. 1a, $k_{a}=0$ and inserting in Eq. (6), $k_{b}$ can be obtained and thus the field from Eq. (5). The functioning of the sensor is presented in [18]. The scattered field must be also focused such that it can be detected by the reception part of the sensor placed in image focal point. EM sensor with MM lens has been realized with two CSRs, tuned at $105 \mathrm{MHz}$ frequency [18], having a large basis face to face. The MM lens assure the possibility to apply of electromagnetic metamaterial in eNDE.

\subsection{Basic Principle of Focused Image}

In order to obtain the good results of the NDT methods, it is necessary to obtain focused images on different planes [26]. Let us consider that the emission part of the sensor generates spherical waves in the material, having $k$ waves number and $R$ the position vector of the scatter. The signal received from a scatter which, assuming an ideal spherical wave, will be

$$
\theta_{H}=c k \sin c(k R),
$$

where $\theta_{H}$ is the phase of the sensor response vs. the incident wave, $c$ is a complex constant and $R=|\bar{R}|$. The sensor scan the surface at the constant height $z_{0}<<\lambda$ and the scatter being located at depth $z_{1}$ below the surface, therefore the distance between sensor and scatter is $z_{0}+z_{1}$. Let $U(x, y, z)$ be the signal delivered by the sensor and $\widetilde{U}\left(x, y, z_{0}\right)$ its two dimensional (2D) Fourier transform, where $u$ and $v$ are spatial frequencies associated to $x$ and $y$ directions. We denote by $\tilde{\theta}(x, y, z)$ the 2D Fourier transform of the point spread function. The filtered and focused signal is given by the 2D Fourier transform of the convolution product of $\widetilde{U}\left(x, y, z_{0}\right)$ by the kernel $\tilde{\theta}(x, y, z)$. 
$A(x, y, z)=$

$\frac{1}{(2 \pi)^{2}} \int_{-\infty}^{\infty} \int_{-\infty}^{\infty} \tilde{U}\left(u, v, z_{0}\right) \tilde{\theta}(u, v, z) \exp j(u x+v y) d u d v$,

The image processed in this way can be obtained with:

$$
I(x, y)=|A(x, y, z)|^{2}
$$

\section{STUDIED SAMPLES}

The $\mathrm{ZrO}_{2}-\mathrm{Y}_{2} \mathrm{O}_{3}$ ceramics has been analyzed in the past years, the most publications presenting the special mechanical properties of the $\mathrm{Y}_{2} \mathrm{O}_{3}$ content structure.

By doping with Yttria, a cation substitutive, supplementary oxygen vacancies are added to the molecular structure, increasing the ionic electrical conductivity. When Yttria is alloyed with zirconia in concentration from $3 \%$ to $20 \%$ (molar percent), the crystalline structure of material in normal conditions is entirely stabilized [27], so that at variation of temperature, microcracking apparition can be avoided. Monolithic coating consisting of various thickness zirconia doped with $3 \%$ to $20 \% \mathrm{Y}_{2} \mathrm{O}_{3}$ deposited on AISI 316L (composition in wt. \% as EN 1.4404, Table 1) have been taken into study.

Table 1. Chemical composition of substrate material

\begin{tabular}{cccccc}
\hline element & $\mathrm{C}$ & $\mathrm{Si}$ & $\mathrm{Mn}$ & $\mathrm{P}$ & $\mathrm{S}$ \\
\cline { 1 - 5 } wt. \% & 0.018 & 0.458 & 1.294 & 0.032 & 0.003 \\
\hline element & $\mathrm{Cr}$ & $\mathrm{Ni}$ & $\mathrm{Mo}$ & $\mathrm{N}$ & \\
\cline { 1 - 5 } wt. \% & 16.815 & 10.086 & 2.004 & 0.032 & \\
\hline
\end{tabular}

The AISI 316L steel may be susceptible to intergranular corrosion in certain corrosive media after it is welded or otherwise heated at temperatures between $430{ }^{\circ} \mathrm{C}$ and $860{ }^{\circ} \mathrm{C}$ [28] and [29]. It has electrical conductivity $1.3513 \times 10^{6} \mathrm{~S} \cdot \mathrm{m}^{-1}$ and thermal expansion coefficient $17.2 \times 10^{-6} \mathrm{~K}^{-1}$ at $473 \mathrm{~K}$. TBC coating were deposited onto AISI 316L samples (20 $\mathrm{mm} \times 80 \mathrm{~mm}$ and $2 \mathrm{~mm}$ height) using plasma torch F 400 with commercial atmospheric equipment APS 100 produced by Plasma-Technik AG.

Monolithic coatings of various thickness consisting of zirconia doped with $20 \% \mathrm{Y}_{2} \mathrm{O}_{3}$ and sandwich zirconia doped with $20 \% \mathrm{Y}_{2} \mathrm{O}_{3}$ and $\mathrm{Y}_{2} \mathrm{O}_{3}$ coatings were deposited on AISI 316L [30]. The coating material is produced by Metco as powder MetcoTM 202NS and Metco 6035A-1 used for plasma spraying, having excellent resistance to oxidation and corrosion at temperature up to $1000{ }^{\circ} \mathrm{C}$ and can create good TBC. Pure yttrium oxide is a highly stable compound with a high melting point, is very inert chemically, and exhibits excellent electrical insulation (volume resistivity and dielectric breakdown strength). The quality of surface of ceramic coating depend on gas flow, power levels, powder particle size distribution, etc. During the deposition, also samples without good adherence at support were obtained, being analyzed as well.

\subsection{Microscopy Analyses}

For TBC the most important parameters are the thickness, thermal conductivity and density of coatings. In order to minimize the residual stresses inside the sandwich coating-alloy support during the heating/cooling, the coating $\mathrm{ZrO}_{2}-\mathrm{Y}_{2} \mathrm{O}_{3}$ shall be characterized- It is difficult to achieve the electronic conductivity balance at $1200{ }^{\circ} \mathrm{C}$ in the conditions of low diffusion of cations in YSZ [31].

In Fig. 2a we are showing the cross sectional image of the sample deposited with $\mathrm{ZrO}_{2}$ with $20 \%$ $\mathrm{Y}_{2} \mathrm{O}_{3}$ with $0.2 \mathrm{~mm}$ thin monolithic coating, using a Zeiss microscope in polarized light with Axio Imager $\mathrm{A} 1 \mathrm{~m}$ and in Fig. $2 \mathrm{~b}$ the cross section of sample deposited with $\mathrm{ZrO}_{2}$ with $20 \% \mathrm{Y}_{2} \mathrm{O}_{3}$ with $0.25 \mathrm{~mm}$ thin monolithic coating using Zeiss microscope $\mathrm{Z} 1 \mathrm{~m}$ with Axio-Vision 4.8.
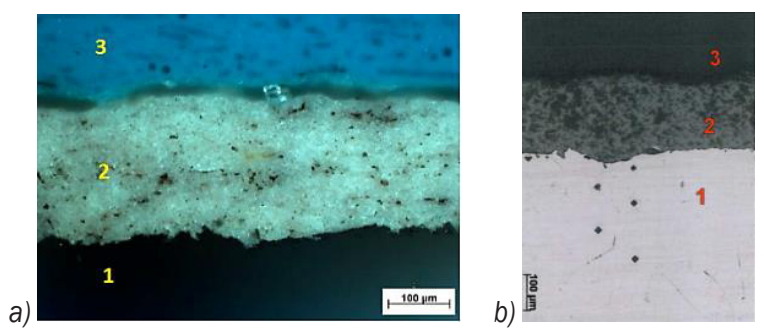

Fig. 2. Metallography: a) of $\mathrm{ZrO} 2$ with addition of $20 \% \mathrm{Y}_{2} \mathrm{O}_{3}$ ceramic coating with $0.2 \mathrm{~mm}$ thickness; $b$ ) of $\mathrm{ZrO}_{2}$ with $20 \% \mathrm{Y}_{2} \mathrm{O}_{3}$ ceramic coating with $0.25 \mathrm{~mm}$ thickness (1 substrate AISI 316L; 2 Zirconia doped with Yttria; 3a Bakelite; 3b air)

The Vickers micro-indentation tests were performing using Shimadzu M device to determine the hardness of zirconia coating to support, the measured value being of $470 \mathrm{HV} 0.05$. Indentations were effectuated on longitudinal and cross section. Information about interface between support and zirconia coating are obtained by SEM and EDX.

Usually, information about porosity of coating is obtained by surface microscopy and soft gray scale threshold setting. This technique is subjective, due to the setting of gray level and light intensity, reflection 
of surface, samples preparation etc. The accuracy of gray scale threshold approach is investigated using image processing in Matlab described in [31].

Taking into account that the structures of YSZ TBC layers deposited on stainless steels are typically porous [30], to obtain relevant information about the influence of yttria concentration over the adherence at support, secondary electrons (SE) images, as well as backscattered electrons (BSE) images have been taken, Figs. 3a and c. In Figs. 3b and d are presented the histograms of voids data.

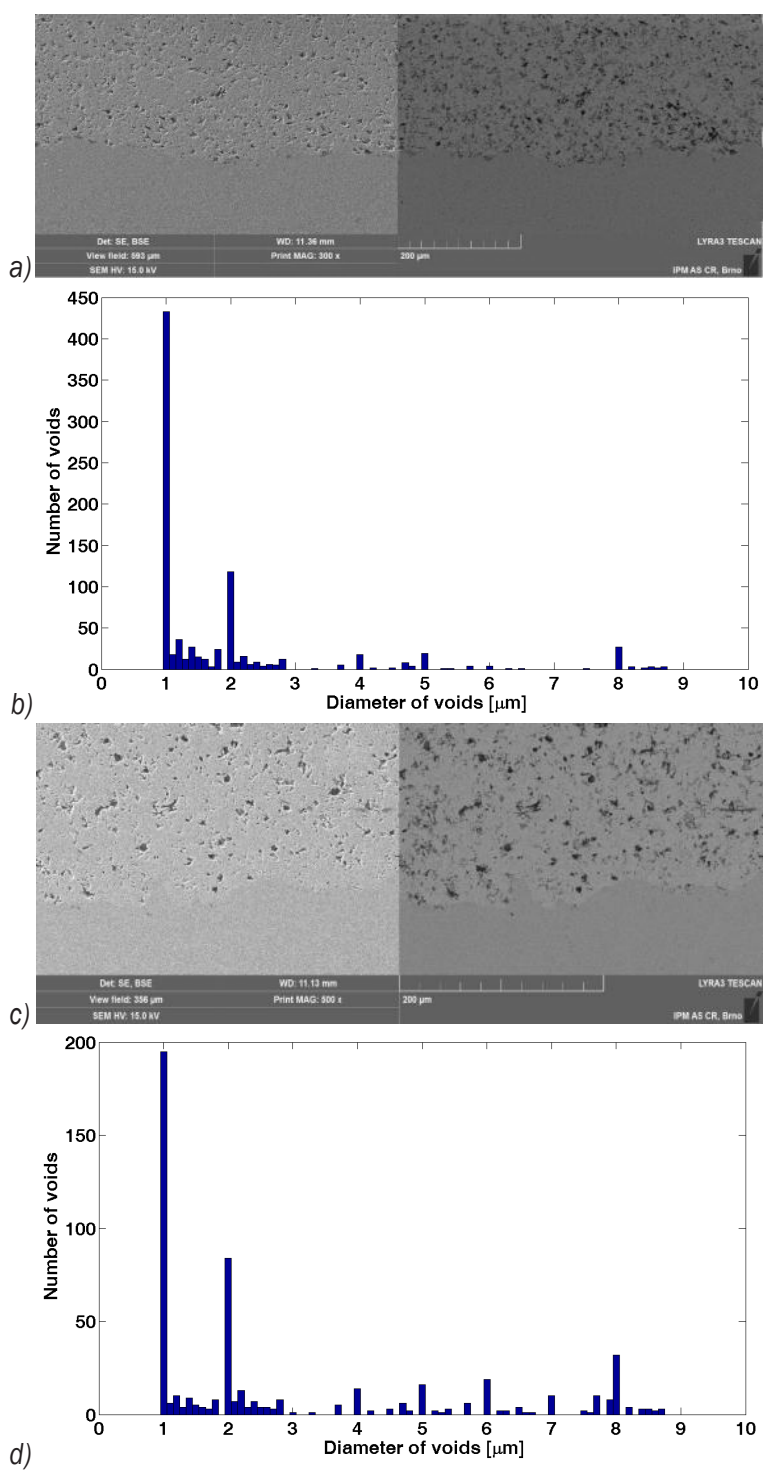

Fig. 3. SEM images ( $a$ and $c$ ) and voids counting ( $b$ and $d$ ): a) and b) for specimen with $0.2 \mathrm{~mm}$ thin monolithic coating $\mathrm{ZrO}_{2}$ with addition of $20 \% \mathrm{Y}_{2} \mathrm{O}_{3} ; \mathrm{c}$ ) and d) for specimen with sandwich coating $0.25 \mathrm{~mm} \mathrm{ZrO}$ with addition of $20 \% \mathrm{Y}_{2} \mathrm{O}_{3}$ and $0.005 \mathrm{~mm}$ $\mathrm{Y}_{2} \mathrm{O}_{3}$
It can be observed that with the doping with $y$ ttria, the voids are larger but their number decreases.

Topographical characterization of the specimen is realized with a TESCAN electron microscope (TESCAN LYRA3 GM) operating at an acceleration voltage of $15 \mathrm{kV}$. The porosity of the tested surface can be evaluated from the SEM images within $0.5 \%$ accuracy.

\subsection{X-Ray Diffraction (XRD) and Neutron Diffraction (ND)}

XRD experiments performed at room temperature on a Philips diffractometer, at JINR Dubna, Russia, allow determination of the phase composition and microstructural parameters by using Fullprof software. The space group and lattice constants were obtained with Ceckcell and proofed by Fullprof software. The comparisons between the diffractogram of the sample formed from a layer of zirconia doped with yttria deposited on a support of AISI316L with the diffractogram of AISI $316 \mathrm{~L}$ and, respectively, with the diffractogram of zirconia doped with yttria allowed to identify austenite maxima ( $\gamma$ ) (Fig. 4) and doped zirconia $(t)$ maxima (Fig. 5).

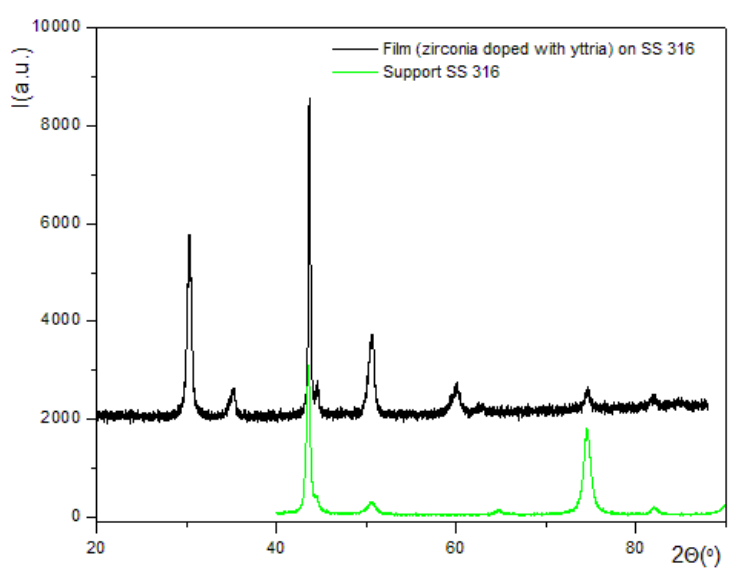

Fig. 4. The Xray diffractograms of support + the layer of zirconia with yttria and of the support

Some ND data were collected by using the high resolution Fourier diffractometer (HRFD) time-of-flight diffractometer from reactor IBR 2 - JINR Dubna, Russia, at room temperature (Fig. 6) corresponding bulk samples of zirconia doped with yttria on bulk samples (ND diffractgrams were calculated also by using FullProf and PowderCell software). We have attempted to determine the conditions in which zirconia doped with yttrium can be identified in the diffractogram of a sample formed by a yttrium-doped zirconia layer and a stainless steel 
support, using the data obtained on zirconia doped with yttria (4\% and $8 \%$ ) bulk sample.

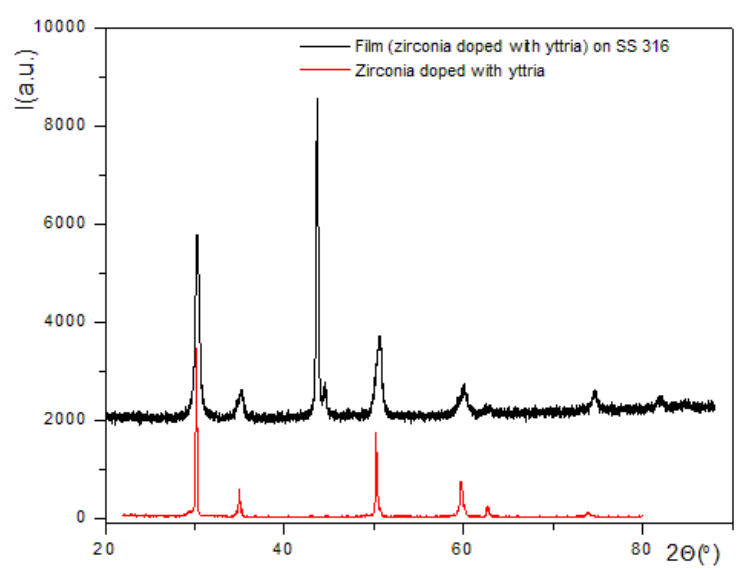

Fig. 5. The $X$ ray diffractograms of support + the layer of zirconia with yttria and of the zirconia with yttria

Transformation of TOF values in $2 \Theta$ values was obtained using the relation:

$$
2 \Theta=\left[\frac{360}{\pi}\right] a \sin \left[\frac{\mathrm{Dtt} 1 \times 0.77026}{\mathrm{TOF}-\mathrm{ZERO}}\right] .
$$

The constants ZERO, Dtt1 and Dtt2 can be determined with a standard (Dtt $2=0$ in this case). The neutrograms were obtained using $\lambda=1.5406 \AA$. The test performed on zirconia doped with yttria ( $4 \%$ to $8 \%$ bulk samples by neutron diffraction at IBR-2 Dubna, Russia indicated the presence of two phases (Fig. 6).

The calculated neutronogram for a sandwich of two layer of zirconia doped with $20 \%$ yttria $(0.25 \mathrm{~mm}$ thickness) and a layer of yttria (0.005 mm thickness) is presented in Fig. 7.

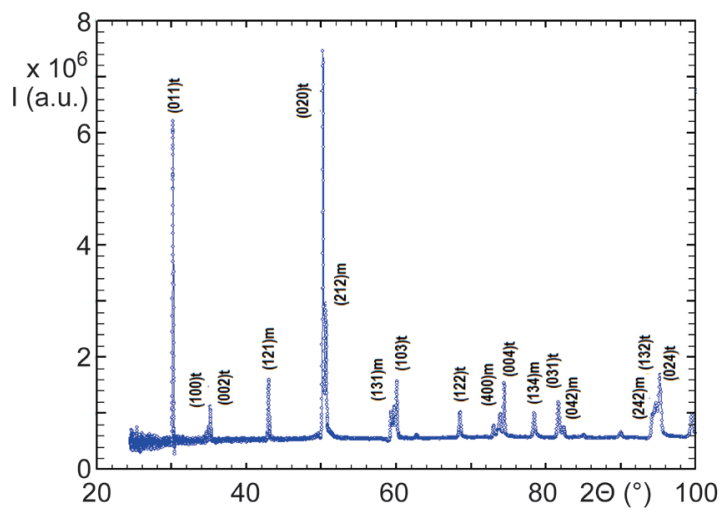

Fig. 6. The neutronogram of $\mathrm{ZrO}_{2}+4 \% \mathrm{Y}_{2} \mathrm{O}_{3}$ bulk sample; the ND data were acquired by using HFRD diffractometer, IBR-2, Dubna, Russia
The both layers are practically transparent for the neutron beam and the volumes of the layers are supposed to be the same. The diffracted intensities corresponding to the layers depend on its relative volumes.

The calculated neutronogram of a mixture between stainless steel, zirconia and yttria, in equal concentrations, is presented in Fig. 7.

We have used a neutron beam with a constant wavelength $(\lambda=1.5406 \AA)$, the same with the wavelength used to obtain the X-ray diffractogram of layer of zirconia deposited on AISI 316 support (Fig. $8)$.

In the first case (XRD) we have a real thin layer of zirconia (about $200 \mu$ ), in the second case (ND) the neutron beam sees equal volumes of the three components of the "phase mixture: steel 316 , zirconia and yttria" (Fig. 7).

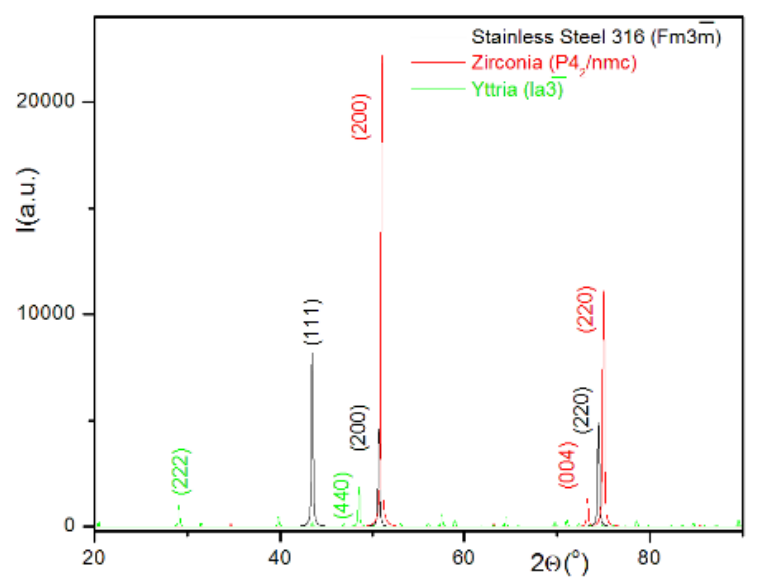

Fig. 7. The calculated diffractogram of the zirconia doped with yttria layer + yttria intermediate layer on AISI 316 support (ND)

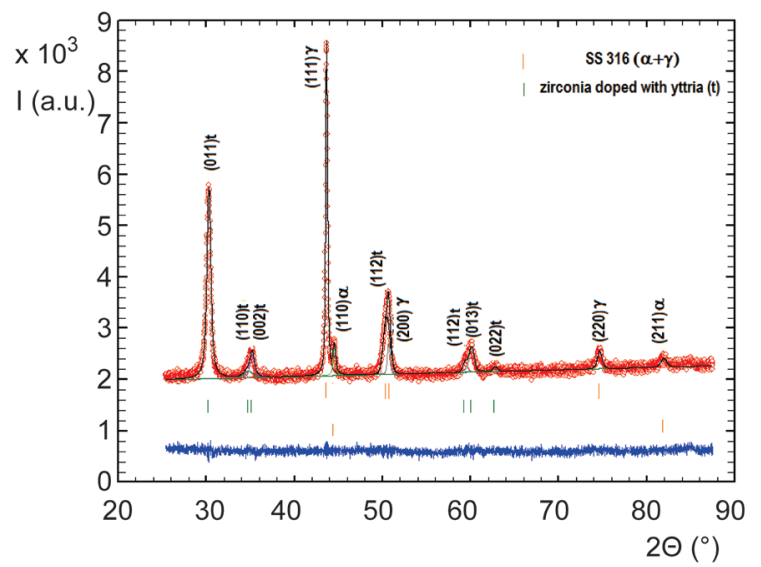

Fig. 8. The observed diffractogram of the zirconia doped with yttria layer on AISI 316L support (XRD) - in blue (curve below) - is the difference between calculated and observed $X$ ray difractogram 
In fact, the concentration ratio of the three phases is 1000: 125: 2.5 . The intensity of maxima corresponding to yttria cannot be observed in this case. We will investigate the yttria+zirconia layers deposited on stainless steel 316 support by neutron reflectometry or by X-ray diffraction.

The difference between the structure of bulk doped with yttrium zirconia and of the deposited layer of yttrium doped zirconia on 316 support will be discussed elsewhere.

\section{EXPERIMENTAL SETUP OF ELECTROMAGNETIC TESTING}

$\mathrm{ZrO}_{2}-\mathrm{Y}_{2} \mathrm{O}_{3}$ used as top-coating (is nonconductive and nonmagnetic) behaves like an air gap between conductive support and EM sensor, creating a lift-off for the EM sensor. The challenge for the development of new types of EM transducers consists in the obtaining of good detection sensitivity for a minimum $3 / 1$ signal to noise ratio as well as a good spatial resolution.

As shown in [22], the sensor with a lens realized with CSR, functioning in the range of frequencies such that $\mu_{\text {eff }}$ is maximum. The detection principle is similar with the one of near-field electromagnetic scanning microscopy (NFESM) [18]. NFSEM imaging is a sampling technique, i.e., the specimen (in this case plate with thickness of coating) is probed point by point by raster scanning with the sensor over the specimen surface and recording for energy image pixel a corresponding electromagnetic signature. Scattered EM field from other regions is eliminated by using MM lens with CSR with a conductive screen with circular aperture (made from perfect electric conductor material, copper foil adhesiveless laminated with $12 \mu \mathrm{m}$ thickness polyimide foil) according to Fig. 9a. The functioning of entire system detection can be described using Fourier optics [32] and [33]. The skin depth is limited by standard penetration $\delta=\sqrt{2 / \omega \mu_{0} \sigma} \quad$ with $\quad \omega=2 \pi f, \quad \mu_{0}=4 \pi \times 10^{-7} \mathrm{Hm}^{-1}$, being vacuum magnetic permeability and $\sigma$ is the electric conductivity of material. The reception coil functions as a detection antenna, converting localized energy into electromotive force.

The eNDE of a material consists in the applying an EM field to the object examined and evaluating the interaction between the field and the eventual material flaws [34] and [35]. To increase the reliability and assure quality, an automatic scanning system is used, $\mathrm{XY}$ displacement system type Newmark together with a high frequency data acquisition [18]. The EM sensor with MM lens, presented above is connected to a Network/Spectrum/Impedance Analyzer type 4395A Agilent USA.

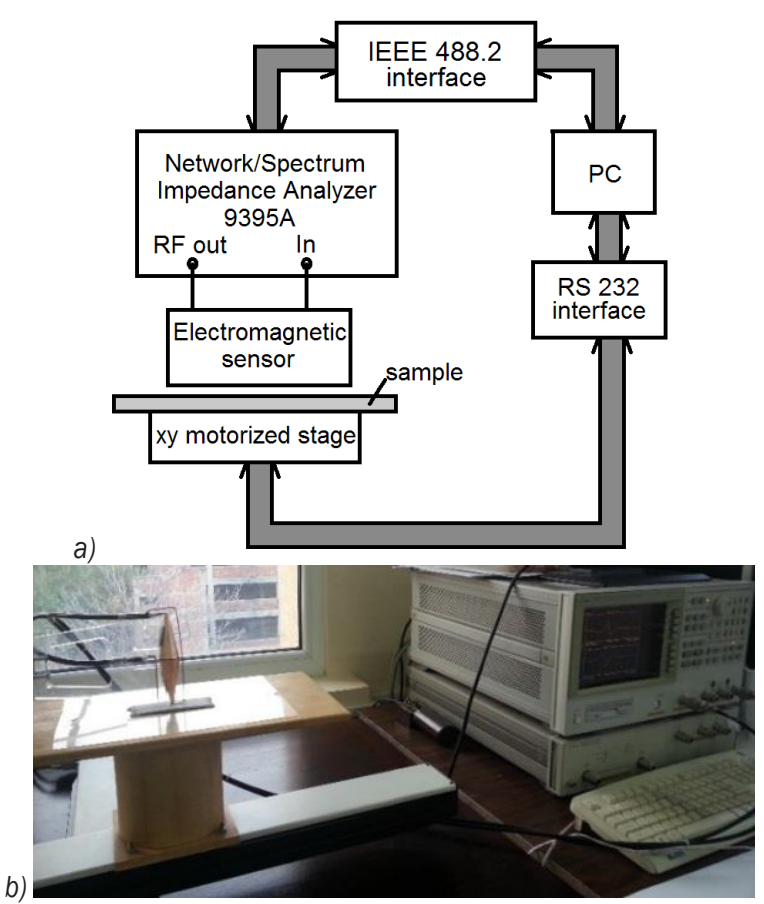

Fig. 9. Experimental setup: a) basic scheme; b) equipment

During the measurements, the sensor was fixed and the samples is mounted on a XY displacement system. That assures the displacement in plan with $\pm 10 \mu \mathrm{m}$ precision and assures the scanning $5 \mathrm{~mm} \times$ $5 \mathrm{~mm}$ surface of sample with $0.1 \mathrm{~mm}$ steps in both directions. A PC allows the command of manipulation and measurement instruments, the data being acquired and stored automatically.

\section{RESULTS OF EM TESTING}

It is possible to appear many cracks due to the relaxation of residual stresses after deposition. The microstructure obtained by plasma jet can present lamellar or flattened splats with micro cracks through the splats or inter-splats. These splats lie parallel to the surface of the coating due to impact of the highspeed molten particles on the substrate. The surface and bonding quality of support-layers are examined [36]. The sensor with MM lens has allowed the identification and estimation of the zones where the nanoparticles have created shear distortions [37], possible to degenerate in the damage of the coatings. The samples were placed on the displacing system, with emission coil perpendicular on the surface and on scanning direction [18]. Ceramic zirconia 


$$
f_{0}(x, y) \rightarrow \begin{gathered}
2 D \quad \text { Fourier } \\
\text { Transform }
\end{gathered} \stackrel{F_{(0)}(u, v)}{\longrightarrow} x \exp \left[-\frac{j 2 \pi^{2}}{k}\left(u^{2}+v^{2}\right)\right] \stackrel{F_{Z}(u, v)}{\longrightarrow} \begin{gathered}
\text { Inverse } 2 D \\
\text { Fourier } \quad \text { Transform }
\end{gathered} \rightarrow f_{Z}(x, y)
$$

Fig. 10. The image modification by an aperture due to Fresnel diffraction

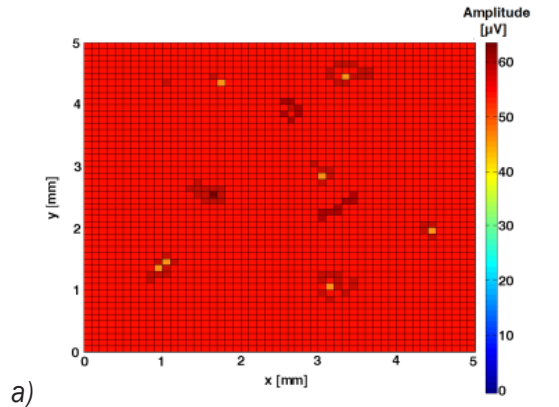

Fig. 11. The amplitude of the voltage induced in the reception coil of the electromagnetic transducer:

a) $0.2 \mathrm{~mm}$ thin monolithic coating $\mathrm{ZrO}_{2}$ with addition of $20 \% \mathrm{Y}_{2} \mathrm{O}_{3}$; b) sandwich coating $0.25 \mathrm{~mm} \mathrm{ZrO}_{2}$ with addition of $20 \% \mathrm{Y}_{2} \mathrm{O}_{3}$ and $0.005 \mathrm{~mm} \mathrm{Y}_{2} \mathrm{O}_{3} ; \mathrm{c}$ ) specimen with nonadherence from $0.25 \mathrm{~mm}$ thin monolithic coating $\mathrm{ZrO}_{2}$ with $20 \% \mathrm{Y}_{2} \mathrm{O}_{3}$ addition top coating is nonconductive and nonmagnetic, this creates a probe lift-off effect. The specimens with 0.2 $\mathrm{mm}$ thickness of zirconia coating with and without yttria were fixed on a Newmark X-Y displacement system, and the image delivered by the assembly sensor-equipment is amplified. In order to improve the spatial resolution, in front of the sensor with MM lens has been placed the circularly aperture $0.1 \mathrm{~mm}$ diameter. This is due to the diffraction on the aperture of the electromagnetic field generated by scattering on the specimen. That assure for the structure of surface clearly visible. Considering an object placed in the plane $z=0$ and described by the function $f_{0}(x, y)$, at passing through an aperture, in the case of Fresnel diffraction (the aperture is closely to the object), the image obtained at the distance $z$ from the object will be $f_{z}(x, y)$ and can be calculated using the algorithm presented in Fig. 10, according to the principle of Fourier optics.

To ensure that $f_{z}(x, y)$ might represent exactly the figure of Fresnel diffraction through the a radius aperture, between the Fourier variables and the spatial ones must be:

$$
d u=\frac{2 a}{N d x_{0}}, \quad d v=\frac{2 a}{M d y_{0}},
$$

where $N$ and $M$ represent the maximum number of measurement points along $x$ and $y$ direction and $d x_{0}$ and $d y_{0}$ are the scanning step along $x$ and respective $y$ directions. Inverting the operation from Fig. 10 , the object $f_{0}(x, y)$ can be determined knowing the diffraction figure $f_{z}(x, y)$. The measurements effectuated with the aperture make that the signals recorded shall represents $f_{z}(x, y)$. The shape of the object that scatters the electromagnetic field created by the emission coil can be determined.

Figs. 11a and $\mathrm{b}$ show the amplitude of the voltage induced in the reception coil of the electromagnetic transducer at the scanning of the two specimens presented above.

Fig. 11c present the scanning of a specimen with no adherence from $0.25 \mathrm{~mm}$ thin monolithic coating $\mathrm{ZrO}_{2}$ with addition of $20 \% \mathrm{Y}_{2} \mathrm{O}_{3}$. It can be observed that the values of emf induced in the reception coils are affected by the material microstructure and by the presence of inhomogeneities on/in the surface of support.

The image corresponding to $0.2 \mathrm{~mm}$ thin monolithic coating $\mathrm{ZrO}_{2}$ with addition of $20 \% \mathrm{Y}_{2} \mathrm{O}_{3}$ do not present nonadherence regions. The amplitude of voltage induced in the reception coil has relatively constant value, excepting the regions where variations appear most probable due to agglomeration of oxides.

Sandwich coatings $0.25 \mathrm{~mm} \mathrm{ZrO}_{2}$ with addition of $20 \% \mathrm{Y}_{2} \mathrm{O}_{3}$ and $0.005 \mathrm{~mm} \mathrm{Y}_{2} \mathrm{O}_{3}$ show that at doping with yttria, the voids are more extended but their number decreases, fact confirmed also by the SEM images.

\section{CONCLUSIONS}

TBC potential depends not only by the intrinsic properties of TBC's material but of the coating microstructure that is determined by the deposition process. Nanocomposites with nanometer - sized second phase particles dispersed in ceramic matrix 
and/or at grain boundaries have shown an ability to withstand thermal cycling at temperatures significantly higher than simple layer YSZ-coatings. They also have significant better strength and creep resistance than other coatings by decreasing the number of voids. Hence the evaluation of the surface structure and possible delamination at the interface of deposited layers for this type of zirconia coating on stainless steel is important.

Further tests on a larger number of specimens with different coating aspects of the surface, influence of surface roughness on stress intensity factor, number of layers are needed to establish the accuracy of the results and the correlation between the located very small defect in size and the results of MM sensor response. Also, the results can be further continues by complementary investigation as $\mathrm{ND}, \mathrm{X}$ ray diffraction or other methods that can emphasize indications about phase composition and structure parameters.

\section{ACKNOWLEDGEMENTS}

This paper is partially supported by Romanian Ministry of Research and Innovation under Nucleus Program PN 2018- 3MAP and Bilateral Cooperation with JINR Dubna under protocol no. 4414-42015/2018.

\section{REFERENCES}

[1] Alvin, M.A., Klotz, K., McMordie, B., Zhu, D., Gleeson, B., Warnes, B. (2014). Extreme temperature coatings for future gas turbine engines. Journal of Engineering for Gas Turbines and Power, vol. 136, no. 11, p. 112102, DOl:10.1115/1.4027186.

[2] Eldridge, J.I., Spuckler, C.M., Martin, R.E. (2006). Monitoring delamination progression in thermal barrier coatings by midinfrared reflectance imaging. International Journal of Applied Ceramic Technology, vol. 3, no. 2, p. 94-104, D0l:10.1111/ j.1744-7402.2006.02067.x.

[3] Tolpygo, V.K., Clarke, D.R., Murphy, K.S. (2004). Evaluation of interface degradation during cyclic oxidation of EBPVD thermal barrier coatings and correlation with TGO luminescence. Surface and Coatings Technology, vol. 188189, p. 62-70, D0l:10.1016/j.surfcoat.200408.001.

[4] Ellingson, W.A., Visher, R.J., Lipanovich, R.S., Deemer, C.M. (2006). Optical NDT techniques for ceramic thermal barrier coatings: NDT of ceramics: an introduction to the technical focus issue. Materials Evaluation, vol. 64, no. 1, p. 45-51.

[5] Pieralli, S., Kohal, R.J., Hernandez, E.L., Doerken, S., Spies, B.C. (2017). Osseointegration of zirconia dental implants in animal investigations: A systematic review and meta-analysis. Dental Materials, vol. 34, no. 2, p. 171-182, D0l:10.1016/j. dental.2017.10.008.
[6] Ceramtec (2017). from: www.ceramtec.com, accessed on 2018-10-27.

[7] Renusch, D., Schütze, M. (2007). Measuring and modeling the TBC damage kinetics by using acoustic emission analysis. Surface and Coatings Technology, vol. 202, no. 4-7, p. 740744, D0I:10.1016/j.surfcoat.2007.07.109.

[8] Ryshkewitch, E., Richerson, D.W. (1985). Oxide ceramics: Physical Chemistry and Technology, Hasskell General Ceramics, New York.

[9] Zhu, W.Z. (1998). Effect of cubic phase on the kinetics of the isothermal tetragonal to monoclinic transformation in $\mathrm{ZrO}_{2}$ $\left(3 \mathrm{~mol} \% \mathrm{Y}_{2} \mathrm{O}_{3}\right)$ ceramics. Ceramics International, vol. 24, no. 1, p. 35-43, DOI:10.1016/S0272-8842(96)00074-0.

[10] Li, P., Chen, I.W., Penner-Hahn, J.E. (1994). Effect of dopants on zirconia stabilization - an X-ray absorption study: I, trivalent dopants. Journal of the American Ceramic Society, vol. 77, no. 1, p. 118-128, D0l:10.1111/j.1151-2916.1994.tb06964.x.

[11] Ren, X., Pan, W. (2014). Mechanical properties of high-temperature-degraded yttria-stabilized zirconia. Acta Materialia, vol. 69, p. 397-406, D0l:10.1016/j. actamat.2014.01.017.

[12] Ėvarestov, R.A. (2015). Theoretical Modeling of Inorganic Nanostructures: Symmetry and ab-initio Calculations of Nanolayers, Nanotubes and Nanowires. Springer, Berlin, DOI:10.1007/978-3-662-44581-5.

[13] Faktorova, D., Novy, F., Fintova, S., Savin, A., Steigmann, R., Iftimie, N., Turchenko, V., Craus, M.L. (2016). Evaluation of zirconia coatings deposited on stainless steel substrate. Electromagnetic Nondestructive Evaluation (XIX), vol. 41, p. 254-262, DOI:10.3233/978-1-61499-639-2-254.

[14] Savin, A., Craus, M.L., Turchenko, V., Bruma, A., Dubos, P.A., Malo, S., Konstantinova, T.E., Burkhovetsky, V.V. (2015). Monitoring techniques of cerium stabilized zirconia for medical prosthesis. Applied Sciences, vol. 5, no. 4, p. 16651682, D0I:10.3390/app5041665.

[15] Limarga, A.M., Shian, S., Baram, M., Clarke, D.R. (2012). Effect of high-temperature aging on the thermal conductivity of nanocrystalline tetragonal yttria-stabilized zirconia. Acta Materialia, vol. 60, no 15, p. 5417-5424, D0l:10.1016/j. actamat.2012.06.054.

[16] Gupta, G.K., Chattopadhyaya, S. (2017). Critical failure analysis of superheater tubes of coal-based boiler. Strojniški vestnik - Journal of Mechanical Engineering, vol. 63, no. 5, p. 287-299, D0l:10.5545/sv-jme.2016.4188.

[17] Wiltshire, M.C.K. (2007). Radio frequency (RF) metamaterials, Physica Status Solidi (b), vol. 244, no. 4, p. 1227-1236, DOl:10.1002/pssb.200674511.

[18] Savin, A., Steigmann, R., Bruma, A., Šturm, R. (2015). An electromagnetic sensor with a metamaterial lens for nondestructive evaluation of composite materials. Sensors, vol. 15, no. 7, p. 15903-15920, Dol:10.3390/s150715903.

[19] Pendry, J.B., Holden, A.J., Robbins, D.J., Stewart, W.J. (1999). Magnetism from conductors and enhanced nonlinear phenomena. IEEE Transactions on Microwave Theory and Techniques, vol. 47, no. 11, p. 2075-2084, DOI:10.1109/22.798002.

[20] Van Bladel, J.G. (2007). Electromagnetic Fields, $2^{\text {nd }}$ ed. IEEE Press: Piscataway, D0I:10.1002/047012458X. 
[21] Liu, X., Hu, G. (2016). Elastic metamaterials making use of chirality: a review. Strojniški vestnik - Journal of Mechanical Engineering, vol. 62 , no. 7-8, p. 403-418, D0I:10.5545/svjme.2016.3799.

[22] Grimberg, R., Savin, A., Steigmann, R., Serghiac, B., Bruma, A. (2011). Electromagnetic non-destructive evaluation using metamaterials. Insight-Non-Destructive Testing and Condition Monitoring, vol. 53, no. 3, p. 132-137, Dol:10.1784/ insi.2011.53.3.132.

[23] Grimberg, R., Tian, G.Y. (2012). High-frequency electromagnetic non-destructive evaluation for high spatial resolution, using metamaterials. Proceedings of the Royal Society A: Mathematical, Physical and Engineering Sciences, vol. 468, no. 2146, p. 3080-3099, Dol:10.1098/ rspa.2011.0666.

[24] Smith, D.R., Vier, D.C., Koschny,Th., Soukoulis, C.M. (2005). Electromagnetic parameter retrieval from inhomogeneous metamaterials. Physical Review E, vol. 71, no. 3, p. 036617 , DOI:10.1103/PhysRevE.71.036617.

[25] Born, M., Wolf, E. (1959). Principles of Optics: Electromagnetic Theory of Propagation, Interference and Diffraction of Light. Pergamon Press, Oxford.

[26] Grimberg, R., Savin, A., Steigmann, R., Bruma, A. (2006). Eddy current examination of carbon fibres in carbon-epoxy composites and Kevlar. International Journal of Materials and Product Technology, vol. 27, no. 3-4, p. 221-228, DOI:10.1504/IJMPT.2006.011272.

[27] Pascual, C., Durán, P. (1983). Subsolidus phase equilibria and ordering in the system $\mathrm{ZrO}_{2}-\mathrm{Y}_{2} \mathrm{O}_{3}$. Journal of the American Ceramic Society, vol. 66, no. 1, p. 23-27, DOI:10.1111/j.1151-2916.1983.tb09961.x.

[28] Chowdhury, S.G., Das, S., Ravikumar, B., De, P.K. (2006). Twinning-induced sluggish evolution of texture during recrystallization in AISI 316L stainless steel after cold rolling. Metallurgical and Materials Transactions A, vol. 37, no. 8, p. 2349-2359, DOl:10.1007/BF02586209.

[29] Matsui, K., Tanaka, K., Yamakawa, T., Uehara, M., Enomoto, N., Hojo, J. (2007). Sintering kinetics at isothermal shrinkage:
II, effect of Y203 concentration on the initial sintering stage of fine zirconia powder. Journal of the American Ceramic Society, vol. 90, no. 2, p. 443-447, Dol:10.1111/j.15512916.2006.01440.x.

[30] Savin, A., Novy, F., Fintova, S., Steigmann, R. (2017). Evaluation of thin discontinuities in planar conducting materials using the diffraction of electromagnetic field. IOP Conference Series: Materials Science and Engineering, vol. 227, no. 1, p. 012115, D0I:10.1063/1.323475.

[31] Hanic, F., Hartmanova, M., Kundracik, F., Lomonova, E.E. (2003). Stabilization and properties of high temperature forms of zirconia. Solid State Phenomena, vol. 90-91, p. 303-308, D0l:10.4028/www.scientific.net/SSP.90-91.303.

[32] Robinson, D., Ramsundar, P., Samantaray, C.B. (2014). Analyzing porosity in thermal barrier coatings: Edge detection of images using MATLAB. 121st American Society of Engineering Education Annual Conference, paper ID: 8672.

[33] Gustafson, S.C. (1995). Book Review: Goodman, J.W. Introduction to Fourier optics. Optical Engineering, vol. 35, no. 5, p. 1513-1513, Dol:10.1117/1.601121.

[34] Langenberg, K.J., Fischer, M., Berger, M., Weinfurter, G. (1986). Imaging performance of generalized holography. Journal of the Optical Society of America A, vol. 3, no. 3, p. 329-339, DOI:10.1364/JOSAA.3.000329.

[35] Savin, A., Steigmann, R., Bruma, A. (2015). Enhancement of spatial resolution using metamaterial sensor in nondestructive evaluation. Emerging Technologies in Non-Destructive Testing VI, p. 569-575, CRC Press, Boca Raton, D0I:10.1201/b1938194.

[36] Dodd, C.V., Deeds, W.E. (1968). Analytical solutions to eddycurrent probe-coil problems. Journal of Applied Physics, vol. 39, no. 6, p. 2829-2838, D0l:10.1063/1.1656680.

[37] Weller, M. (1994). Mechanical loss measurements on yttria-and calcia-stabilized zirconia. Journal of Alloys and Compounds, vol. 211-212, p. 66-70, D0l:10.1016/09258388(94)90449-9. 